\title{
A formação continuada do pedagogo numa perspectiva reflexiva
}

\author{
The continuous training of the pedagogist in a reflective perspective
}

Rose Maria Zaionz da Rocha Carvalho Especialista em Políticas Públicas Bolsista pela CAPES

Pontifícia Universidade Católica do Paraná - PUC. Curitiba, Paraná, Brasil. zaionzdarocha@gmail.com

D Marcelo Bolfe
Mestre em Educação
Bolsista pela CAPES
Pontifícia Universidade Católica do Paraná - PUC.
Curitiba, Paraná, Brasil.
marcelobolfe@gmail.com

Evelise Maria Labatut Portilho

Doutora em Educação

Pontifícia Universidade Católica do Paraná - PUC.

Curitiba, Paraná, Brasil.

eveliseportilho@gmail.com

Resumo: O pedagogo é o profissional no interior das instituições educativas responsável pela formação continuada dos docentes, sendo, portanto, necessário, a busca constante pela qualificação. Com o intuito de pesquisar a identidade deste profissional num processo de reflexão, o grupo de pesquisa Aprendiz agem e Conhecimento na Formação Continuada do Pedagogo (PUCPR) ofertou no segundo semestre de 2018, um programa de formação continuada. Participaram 16 pedagogos da rede pública e privada de ensino de Curitiba-PR e região metropolitana. Este artigo tem como objetivo compreender a percepção dos pedagogos participantes de um programa de formação continuada que oportunizou a reflexão sobre a aprendizagem com vistas ao autodesenvolvimento. A metodologia adotada foi a qualitativa na visão da fenomenologia hermenêutica. Para análise foi utilizado o protocolo de observação do pri meiro encontro de formação e três questões da entrevista semiestruturada. Como resultado do estudo, constatou-se que a formação continuada se ratifica como uma condição importante para a ressignificação e reorganização das ações, pois possibilita a reflexão do sujeito e dos espaços de aprendizagem, permitindo transformar-se dentro de um processo de emancipação para o desenvolvimento profissional. Constata-se que na rede pública a formação continuada ocorre de forma única, a mesma formação é oferecida para professores, gestores e pedagogos enquanto na rede privada acontece por meio de assessorias especializadas com o intuito de atender aos problemas latentes.

Palavras chave: aprendizagem; formação continuada; pedagogo; reflexibilidade.

Abstract: The pedagogue is the professional within the educational institutions responsible for the continuing education of teachers, therefore, the constant search for qualification is necessary. In order to research the professional identity of this professional in a process of reflection, the research group Learning and Knowledge in Pedagogue Continuing Education (PUCPR) offered a continuing education program in the second half of 2018. Sixteen pedagogues from the public and private schools of Curitiba-PR and the metropolitan region participated. This article aims to understand the perception of pedagogues participating in a continuing education program that provided opportunities for reflection on learning with a view to self-development. The methodology adopted was qualitative in the view of hermeneutic phenomenology. For analysis, the observation protocol of the first training meeting and three ques tions from the semi-structured interview were used. As a result of the study, it was found that continuing education is ratified as an important condition for the redefinition and reorganization of actions, as it enables the reflection of the subject and learning spaces, allowing it to be transformed into a process of emancipation for the professional development. It appears that in the public network, continuing education occurs in a unique way, the same training is offered to teachers, managers and pedagogues, while in the private network it happens through specialized advisory services in order to address latent problems.

Keywords: learning; continuing education; pedagogue; selflection.

Cite como

(ABNT NBR 6023:2018)

CARVALHO, Rose Maria Zaionz da Rocha; BOLFE, Marcelo; PORTILHO, Evelise Maria Labatut. A formação continuada do pedagogo numa perspectiva reflexiva. Dialogia, São Paulo, n. 40, p. 1-21, e21066, jan./abr. 2022. Disponível em: https://doi.org/10.5585/40.2022.21066.

American Psychological Association (APA)

Carvalho, R. M. Z. da. R., Bolfe, M., \& Portilho, E. M. L. (2022, jan./abr.) Comportamentos indisciplinados em sala de aula: o que professores e estudantes pensam e fazem. Dialogia, São Paulo, 40, p. 1-21, e21066. https://doi.org/10.5585/40.2022.21066. 


\section{Introdução}

Este artigo faz parte da Pesquisa Aprendizagem e Conhecimento na Identidade Profissional do Pedagogo (PUCPR), que ofereceu à comunidade escolar um programa de formação continuada para pedagogos em 2018.

O pedagogo escolar é o profissional responsável por coordenar, no âmbito da escola, as atividades de planejamento, avaliação e desenvolvimento profissional, elaborar, implementar, acompanhar e avaliar planos, programas e projetos de ensino da escola, zelar pelo cumprimento da legislação e normas educacionais e pelo padrão de qualidade de ensino, ações elencadas no Edital 17/2013 do Concurso para Pedagogos da Secretaria de Educação do Estado do Paraná - SEED.

É o profissional que desempenha multitarefas no ambiente escolar. Suas ações perpassam por práticas pedagógicas referentes ao ensino e a aprendizagem, como também a gestão de pessoas e dos processos educativos, que no contexto atual perpassam por análises de políticas educacionais que envolvem ações quantitativas e qualitativas. Conforme Libâneo (2010, p. 52), “O pedagogo é um profissional que lida com fatos, estruturas, contextos, situações, referentes à prática educativa em suas várias modalidades e manifestações".

As mudanças ocorridas na prática profissional do pedagogo escolar, foram se intensificando com as mudanças políticas, econômicas, tecnológicas e sociais. A escola absorve essas diferentes demandas, pois está envolvida em todo esse contexto. Para Namarim e Portelinha (2019, p.201) "conforme as demandas sociais se modificam e o mercado de trabalho vai alterando o perfil profissional, assim também acontece com os profissionais da educação e com as demandas da escola".

Em um ambiente de transformações, o papel do pedagogo é preponderante para articulação dos processos na escola, o que requer aperfeiçoamento, assim, a formação continuada é indispensável para a superação das dificuldades, a reflexão sobre a prática profissional e a busca de aperfeiçoamento técnico.

Para Breckenfeld (2009), a formação continuada do pedagogo assume na atualidade o papel de possibilitar a melhora na qualidade da educação, fundamentados nos princípios da equidade e da justiça social. Ressalta que é preciso romper com modelos ultrapassados que enfatizavam a reprodução, sendo necessário incorporar uma nova postura pedagógica fundamentada na investigação, no diagnóstico da realidade e enfocando os processos pedagógicos.

A formação continuada para Tardif (2014), concentra-se na necessidade de vivenciar situações diversificadas com os seus pares de forma colaborativa. Os momentos vivenciados entre 
pedagogos possibilitam o pensar sobre as semelhanças e diferenças nos processos pedagógicos levando-os a refletir, possibilitando segurança e conhecimento para a superação dos problemas.

A reflexão sobre a própria prática e a aprendizagem a partir da mesma, pode levar o pedagogo a uma ação transformadora, para Freire (2001), é o movimento realizado entre o fazer e o pensar, entre o pensar e o fazer que oportuniza a reflexibilidade crítica sobre as práticas em um movimento dialético, a partir da construção e reconstrução do cotidiano escolar.

A compreensão de que a formação continuada do pedagogo é uma ação contínua na caminhada para o desenvolvimento profissional, pode refletir na transformação do coletivo escolar. Entretanto é preciso fortalecer momentos de aprofundamento e instrumentalização teórica e prática visando mudanças didático-pedagógicas qualitativas no âmbito educacional.

No desenvolvimento profissional do pedagogo, as formações precisam contemplar práticas formativas dentro de um contexto crítico-reflexivo que o conduzam ao pensamento autônomo, livre e criativo (NÓVOA, 1991). Neste sentido, não basta o acúmulo de cursos e certificados, é necessário a mudança na ação prática que respalda a transformação, repercutindo na qualidade da educação.

$\mathrm{Na}$ formação do pedagogo é fundamental o exercício crítico tecendo as relações da prática e da teoria. Segundo Pimenta (2005, p.26) “O papel da teoria é oferecer aos professores perspectivas de análises para compreender os contextos históricos, sociais, culturais, organizacionais, e de si mesmos como profissionais, nos quais se dá sua atividade docente, para neles intervir, transformando-os".

Dentro deste contexto, este artigo tem como objetivo compreender a percepção dos pedagogos participantes de um programa de formação continuada que oportunizou a reflexão sobre a aprendizagem com vistas ao autodesenvolvimento.

\section{A formação continuada do pedagogo: algumas reflexões}

A formação continuada do pedagogo é um aporte para o desenvolvimento profissional, pois a sociedade do século XXI se caracteriza por mudanças cotidianas, rapidez nas informações e transformações, sendo necessário a formação ao longo da vida, seja de forma sistematizada ou mesmo de forma empírica.

Visando o aprofundamento e a instrumentalização teórica do pedagogo para o enriquecimento de sua práxis, a formação continuada dentro da escola ou fora dela, segundo Silva (2021, p. 119), [...] "possui indiscutível importância na constituição dos saberes dos professores e pedagogos". 
É por meio da formação continuada que o pedagogo fortalece os seus conhecimentos, possibilitando a mudança na ação pedagógica, o que oportuniza melhor compreensão do fazer didático e técnico, sem perder o caráter educativo, percebendo assim quem são os sujeitos de seu trabalho, o professor e o estudante, num movimento emancipatório e reflexivo.

Silva (2021, p. 150), descreve o pedagogo como um profissional "essencial para que a vida na escola aconteça; é ele que dá suporte às iniciativas pedagógicas dos professores, ao mesmo tempo em que articula as orientações advindas da rede de ensino ou da direção escolar".

Para atender toda dimensão do trabalho do pedagogo escolar que perpassa entre o fazer pedagógico e o técnico, ocorre a necessidade de aperfeiçoamento constante, sendo a formação continuada um dos caminhos para as possíveis mudanças na prática pedagógica.

As pesquisadoras Portilho, Parolin e Barbosa (2021) argumentam da necessidade de instrumentalização do pedagogo para o desenvolvimento do trabalho no coletivo escolar, respeitando as individualidades e considerando a dialética na formação humana propiciando assim o desenvolvimento da equidade.

Entretanto, o modelo de formação continuada oferecido aos pedagogos nem sempre atende as demandas da área de atuação, pois participam dos mesmos processos formativos oferecidos aos professores, desconsiderando a especificidade do trabalho como o planejamento macro escolar, orientação do planejamento didático-metodológico, organização dos tempos e dos espaços, as discussões acerca da transposição didática dos conteúdos do currículo escolar, entre outros.

A formação continuada dentro da especificidade do trabalho do pedagogo pode levar ao conhecimento, a reflexão e a interação com seus pares, permitindo a troca de experiências, a constituição de práticas coletivas e pertinentes aquela determinada realidade, promovendo um exercício de reflexibilidade crítica em direção a construção e reconstrução do trabalho pedagógico.

Ao interpretar, construir e reconstruir a sua prática o pedagogo inicia um processo de autorreflexão, ou seja, um movimento metacognitivo. Segundo Portilho (2011, p. 109) "A possibilidade do sujeito para elaborar suas próprias ações de regulação é, sem dúvida, a apropriação mais significativa do conhecimento".

O pedagogo ao compreender a importância de estudar ao longo de sua carreira, junto a seus pares, pode ressignificar a sua prática e oportunizar mudanças no coletivo de sua escola, por isso é tão importante esse olhar autorreflexivo para a sua prática. Para que se efetive este mecanismo de ressignificação da ação, é importante a superação da formação técnica para a formação reflexiva. 


\section{O caminho metodológico}

Esse estudo faz parte da pesquisa Aprendizagem e Conhecimento na Identidade Profissional do Pedagogo, desenvolvida pelo Grupo de Pesquisa Aprendizagem e Conhecimento na Prática Docente do Programa Stricto Sensu em Educação da PUCPR.

A pesquisa adotada é de caráter qualitativo com abordagem fenomenológica hermenêutica, pois permite a interpretação de forma reflexiva e contextualizada, esclarecendo o fenômeno e oportunizando assim um olhar para o todo. Esta abordagem busca entender o sentido da existência, que deve ser observada precisamente, pois ao contrário fica encoberto na manifestação do dado. Compreender além dos detalhes é fundamental na leitura e intepretação por parte do pesquisador, pois a fenomenologia hermenêutica, possibilita uma visão crítica, desde a verificação dos fenômenos até o modo de esclarecê-los e estudá-los em sua totalidade.

Esta pesquisa oportunizou o desenvolvimento de um programa de formação continuada para pedagogos, com início no ano de 2018. Os temas dos oito encontros foram: $1^{\circ}$ Formação Continuada e Autoformação; $2^{\circ}$ - Identidade Profissional; $3^{\circ}$ - Comunicação Inovadora e Integradora; $4^{\circ}$ - A Expressão da Cultura no Ambiente Educativo; $5^{\circ}$ - Grupo: uma unidade em funcionamento; $6^{\circ}$ - Mediação no Processo de Aprendizagem e Ensino; $7^{\circ}$ - Avaliação, Registro e Devolutiva e $8^{\circ}$ - Entrevista semiestruturada.

Participaram da formação 16 pedagogos de diferentes instituições de ensino da rede pública e privada de ensino do município de Curitiba e região metropolitana, sendo 15 do sexo feminino e 01 do sexo masculino. Quanto à formação todos possuem graduação em Pedagogia e 01 possui a segunda graduação em Filosofia.

Em relação ao local de trabalho, três pedagogos trabalham no ensino privado, doze pedagogos trabalham no ensino público e um em ambas. Os segmentos que atuam são: dois pedagogos trabalham somente na educação infantil, um pedagogo no ensino fundamental II, dois pedagogos com o ensino médio, um pedagogo em outro espaço educacional, outros três pedagogos atuam no ensino fundamental II, ensino médio e outros, três pedagogos atuam no ensino fundamental II e ensino médio, dois pedagogos atuam na educação infantil e ensino fundamental I e dois pedagogos atuam no ensino médio e outros.

Sobre o tempo de atuação profissional como pedagogo, sete trabalham na área de 5 a 7 anos, dois de 8 a 10 anos, quatro de 11 a 13 anos, um de 17 a 19 anos e dois de 20 a 25 anos, demonstrando ser um grupo de profissionais com experiência no campo pedagógico.

Para a análise dos resultados foram utilizados dois instrumentos: a roda de conversa do $1^{\circ}$ Encontro do Programa de Formação Continuada e Autoformação e a Entrevista semiestruturada 
que foi aplicada no $8^{\circ}$ encontro composta por vinte e duas questões, mas para este artigo foram utilizadas as questões 8,9 e 11 .

$\mathrm{O} 1^{\circ}$ Encontro denominado - Formação continuada e autoformação, foi registrado por dois observadores do Grupo de Pesquisa que realizavam os registros de todas as falas e também dos movimentos do grupo. Os encontros foram organizados sempre em três momentos: disparador, roda de conversa, tarefa e avaliação metacognitiva. No disparador, era apresentado alguma atividade, dinâmica ou prática que levasse o grupo a pensar na temática abordada em seguida. Na sequência foi realizada uma apresentação teórica-reflexiva sobre o tema. A roda de conversa era o espaço no qual os participantes eram convidados a discutir o tema sempre a partir de uma consigna inicial. Em seguida, era explicado sobre a tarefa a ser entregue no próximo encontro. Finalizando com a avaliação metacognitiva, um instrumento elaborado pelos pesquisadores com o objetivo de aprender a aprender.

Para a roda de conversa os participantes foram orientados pelo coordenador a observar os objetos que se encontravam no centro e escolher aquele que melhor representasse o seu processo de formação profissional.

Entre os objetos, estavam dispostos: rosário, lanterna, caneta, bloco em branco, jaleco, revista, relógio, livro, marcador permanente entre outros. Após a escolha dos objetos pelos pedagogos, a coordenadora solicitou que relatassem o que levou a escolha do objeto para representar a sua profissão.

$\mathrm{Na}$ sequência do encontro, após as explanações dos participantes, ocorreu o momento de reflexão e embasamento teórico dentro do contexto apresentado. A coordenadora contextualizou sobre a formação e apresentou um pesquisador do Grupo que deu sequência as atividades, apresentando um vídeo denominado "Aprender a aprender". Logo após, os pedagogos foram convidados a compartilhar com o grupo os aspectos que foram relevantes para sua autoformação pedagógica.

O segundo instrumento utilizado nesta análise foi uma entrevista semiestruturada, que é uma técnica utilizada nos trabalhos qualitativos empíricos, constituem-se como "uma conversa a dois ou entre vários interlocutores, realizada por iniciativa de um entrevistador e destinada a construir informações pertinentes a determinado objeto de investigação" (MINAYO; COSTA, 2018).

Este instrumento foi aplicado no $8^{\circ}$ encontro que foi o encerramento da primeira etapa do curso oferecido aos pedagogos. A escolha da entrevista semiestruturada permitiu ao pesquisador um olhar interpretativo e crítico sobre os dados em todo o processo investigativo e interpretativo, 
obtendo significados subjetivos, considerando também as subjetividades que emergiram da experiência de cada sujeito.

Para interpretação dos dados e realização das análises das repostas optou-se por criação de categorias, a partir da fenomenologia hermenêutica, pois essa abordagem permite a compreensão mais aprofundada dos fenômenos. Optou-se pela classificação, criando categorias de interpretação levando em consideração a parte comum que existe entre eles. Assim foram elencadas três categorias: a primeira - construção de novos conhecimentos, a segunda - compartilhamento de informações e a terceira - ações formativas.

As questões da entrevista foram elaboradas coletivamente pelos pesquisadores do Grupo de Pesquisa e apresentaram perguntas referentes à identificação, como: dados pessoais, formação inicial e continuada, experiência profissional e 18 questões abertas sobre o cotidiano do trabalho pedagógico. Os próprios pesquisadores realizavam as entrevistas com os pedagogos, as mesmas foram gravadas (áudio) e depois transcritas.

Para essa análise foram utilizadas três questões que abordam a formação continuada são elas: Como você identifica a necessidade de formação continuada na sua escola? Quais as suas contribuições para a formação continuada de professores na escola que atua? De que maneira a escola em que você trabalha contribui para a sua formação profissional?

A pesquisa contou com a aprovação do Comitê de Ética em Pesquisas com Seres Humanos da Pontifícia Universidade Católica do Paraná (CAAE nº 87390517.80000.0020).

\section{Descrição e interpretação dos dados}

Para atender ao objetivo da pesquisa, em identificar a percepção dos pedagogos em formação continuada diante da oportunidade de refletir sobre a sua aprendizagem com vistas ao autodesenvolvimento, destaca-se o $1^{\circ}$ Encontro da Formação Continuada, denominado Formação Continuada e Autoformação, em especial o momento da roda de conversa cuja consigna inicial foi: diante das experiências aqui vivenciadas e considerando o seu processo de vida profissional, compartilhem no grupo os aspectos que vocês consideram relevantes para a autoformação pedagógica.

Para a interpretação das falas dos pedagogos no $1^{\circ}$ Encontro, foram trazidos os relatos. Os dados foram interpretados sob à luz da fenomenologia hermenêutica, pois permite revelar e interpretá-los de forma reflexiva e ir além do que se sabe sobre o fenômeno apresentado e aprender sobre ele. 
Após a escolha dos elementos selecionados pelos pedagogos que os identificam e os constituem como sujeito do fazer pedagógico, os dados foram transcritos e categorizados emergindo três categorias para melhor interpretação dos dados. Segundo Gomes (2005, p. 185), para organizar os dados é preciso:

[...] adotar uma classificação a partir das formas como foram construídos ou recolhidos, como por exemplo: material gerado a partir das entrevistas (individuais ou grupais); material de observação participante [...]. Após esse primeiro passo, avança-se para uma segunda etapa: preparação e reunião do material de cada classificação inicial; avaliação de sua qualidade e elaboração de estruturas de análise.

Diante das análises, surgiram as seguintes categorias: Aprendizagem, Ensino e Percepção.

A seguir, apresenta-se a descrição das categorias seguida das reflexões dos pedagogos sobre cada objeto escolhido, representando a sua autoformação pedagógica.

A primeira categoria referente a Aprendizagem diz respeito ao envolvimento do pedagogo visando aprender a aprender. De acordo com os pedagogos P02, P16, P18, eles relatam que a busca constante por atualização, novos saberes e confiança mútua são essenciais na prática do pedagogo:

P2: Para mim o livro de Paulo Freire é muito importante, desde que fiz a leitura do livro percebi a importância da missão e comprometimento com a educação, do trabalho parceiro, é uma leitura e reflexão que emociona.

P16: Eu peguei a Revista Veja, temos de estar sempre atualizados, preciso ter também autonomia e desejo de buscar novos saberes.

P18: Eu peguei a lanterna, creio que na minha profissão tenho que sempre buscar luz, a luz da teoria, a luz da prática e da ajuda dos colegas.

A partir das falas evidenciadas na roda de conversa, pôde-se constatar que os pedagogos se encontram desafiados na construção de novos saberes e um processo de atualização constante para o desenvolvimento dos sujeitos envolvidos no processo educativo.

Para Garcia (1996), os profissionais precisam se preparar para assumir os desafios e lidar com a realidade dos educandos, incorporando o saber que ele traz ao ingressar na escola, valorizando sua cultura, promovendo o diálogo e compreendendo a realidade como condição indispensável para poder interferir e transforma-la.

Ainda para Freire (2001, p. 42), a prática docente crítica, implicante do pensar certo, renvolve o movimento dinâmico, dialético, entre o fazer e o pensar sobre o fazer.

Assim, a pratica pedagógica não se resume somente no fazer, ou seja, é necessário que o pedagogo articule e reflita sobre todos os processos pedagógicos dentro de um contexto que oportunize a reflexão no coletivo para a tomada de decisão. 
A segunda categoria denominada Ensino, diz respeito ao processo de ensino, ou seja, como o pedagogo transmite seu conhecimento. As falas de P6, P22, P24 e P25:

$$
\begin{aligned}
& \text { P6 - O jaleco porque tem me coberto de coisas boas. } \\
& \text { P22 - Escolhi a caneta, pois nós deixamos marcas na vida da criança e precisamos ter } \\
& \text { responsabilidade para deixar boas marcas. } \\
& \text { P24 - Eu peguei o pincel, remete a uma formação que faz olhar o ser de maneira integral. } \\
& \text { P25 - Escolhi o bloco em branco, a cada dia vamos escrevendo novas histórias, pois } \\
& \text { nosso processo de formação é constante. }
\end{aligned}
$$

Percebe-se pelo relato dos pedagogos que o ensinar vai além da transmissão de conhecimentos, ou seja, é um processo que requer por parte dos sujeitos envolvidos a doação e a responsabilidade em mediar o processo educativo e a produção de conhecimento.

A terceira categoria denominada de Percepção, diz respeito ao espaço/tempo e a crença em acreditar em um ser supremo.

P10 - Escolhi o relógio, acho que tudo é questão de tempo, temos que tentar organizar o nosso tempo.

P21: Peguei o rosário que simboliza a fé, a esperança, temos que confiar, ter afeto e acreditar no outro.

Os relatos indicam a preocupação e o desejo no processo de busca de conhecimento, essencial para que se favoreça um espaço-tempo capaz de permitir a reflexão crítica e o desenvolvimento de ações que permita compreender o contexto da comunidade educativa possibilitando novas alternativas de saberes e fazeres para reelaboração da prática.

As questões selecionadas da entrevista subsidiaram o olhar para a formação continuada do pedagogo escolar. São elas: 1) Como você identifica a necessidade de formação continuada na sua escola? 2) Quais as suas contribuições para a formação continuada de professores na escola que atua? 3) De que maneira a escola em que você trabalha contribui para a sua formação profissional? No conjunto das respostas sistematizadas foi possível agrupar os temas em três categorias: a primeira referente a necessidade de construção de novos conhecimentos, a segunda com relação ao compartilhamento de informações e a terceira sobre diversidade de ações formativas. Após a análise qualitativa dos dados obtidos e a relação dessas categorias, foram elencadas as subcategorias, conforme apresentadas no Quadro 01. 
Quadro 1 - Definição das categorias de interpretação

\begin{tabular}{|c|c|}
\hline $\begin{array}{c}\text { Categoria } 1 \\
\text { Construção de novos conhecimentos }\end{array}$ & $\begin{array}{c}\text { SUBCATEGORIA } \\
\text { Troca de experiências } \\
\text { SUBCATEGORIA } \\
\text { Planejar novas ações }\end{array}$ \\
\hline $\begin{array}{c}\text { Categoria } 2 \\
\text { Compartilhamento de informações }\end{array}$ & $\begin{array}{l}\text { SUBCATEGORIA } \\
\text { Necessidades } \\
\text { SUBCATEGORIA } \\
\text { Planejamento }\end{array}$ \\
\hline $\begin{array}{c}\text { Categoria } 3 \\
\text { Ações formativas }\end{array}$ & $\begin{array}{c}\text { SUBCATEGORIA } \\
\text { Formação externa } \\
\text { SUBCATEGORIA } \\
\text { Troca de experiências }\end{array}$ \\
\hline
\end{tabular}

Fonte: Os autores, 2021.

A seguir apresenta-se a descrição de cada uma das três categorias e suas respectivas subcategorias de modo a facilitar a compreensão dos resultados apresentados.

A categoria 1 - Construção de novos conhecimentos, aborda a inovação nas práticas, déficit na formação inicial e a formação no próprio lócus de trabalho e a transformação da realidade. Nesta categoria foram elencadas duas subcategorias: troca de experiências e planejar novas ações, elas demonstram um apelo dos participantes em relação a mudança na forma como a formação continuada é organizada pela rede de ensino. Relatam que as mesmas seguem um modelo engessado que não oportunizam vivenciar as necessidades do coletivo. Essas constatações emergiram a partir dos dados coletados durante as respostas das perguntas, conforme relato dos pedagogos ${ }^{1}$ abaixo:

P2 - Bem deficitário, precisa repensar isso de acordo com uma necessidade realmente da escola, dos educandos e dos professores.

P4 - A gente encontra resistência por parte até da direção, a gente quer fazer algo diferente do que no molde que está sendo mandado pela SEED. Porque sempre é a mesma coisa, eles não têm nem o trabalho de reformular, sempre o mesmo material no mesmo formato.

P6 - Olha, os temas que são trazidos da SEED eu creio que não são tão válidos. Se nos deixassem pensar aquilo que é da escola seria mais válido, seria mais aproveitado.

P8 - Eu identifico que ela vem pronta pelo núcleo, sempre assim, principalmente no CEBEJA nunca está de acordo com a realidade da escola porque vem temas mais relacionados as escolas regulares, então nós enquanto pedagogos a gente tenta abordar alguns assuntos que vem pronto e colocar outros que vem de encontro junto com a realidade do nosso educando e dos professores.

\footnotetext{
${ }^{1}$ Não houve intervenção dos pesquisadores nos relatos trazidos pelos pesquisados, os quais são identificados pela letra " $\mathrm{P}$ ” para manter o anonimato.
} 
No relato dos entrevistados acima, percebe-se a insatisfação dos pedagogos em relação aos cursos e temas das formações concedidas na rede de ensino que trabalham, porém é importante esclarecer que não cabe ao pedagogo definir os temas e a metodologia das formações, as mesmas são planejadas e organizadas pela rede de ensino, sendo o pedagogo responsável somente pela execução.

Conforme Placco, Almeida e Souza (2015, p. 19) "Em primeiro lugar, é necessário que se esclareça que quem planeja e organiza a formação dos professores das escolas, em geral, são as Secretarias de Educação do Estado e do Município."

Segundo as autoras, o planejamento das formações continuadas é organizado por técnicos, porém, devido a sua padronização descontextualizada da realidade de cada comunidade escolar, a equipe pedagógica acaba reproduzindo temas que por vezes não fazem sentido no espaço educacional.

Verificamos nos relatos dos pedagogos a preocupação com uma formação continuada que atenda as situações do cotidiano escolar, com maior sensibilidade da mantenedora frente a alguns problemas evidenciados na prática diária, citamos o relato das entrevistadas abaixo:

P3 - Justamente pelas demandas que andam aparecendo nos últimos tempos.
P11 - Olha eu penso que a gente deveria ter mais autonomia na discussão, pois são poucos
dias em que é ofertado dentro do calendário, pode até ser eficaz se a gente tivesse
autonomia de decisão. Cada escola tem sua peculiaridade, aqui na nossa eu vejo a evasão
escolar, até mesmo do período da tarde, bem preocupante, com uma defasagem, com suas
dificuldades, temos acho que uma boa demanda de estudantes laudados, com dificuldades
mesmo de aprendizagem, que a forma de trabalho deveria ser diferente e que por mais
que a gente expresse isso no conselho de classe, falta conhecimento teórico e falta ...
realmente promover essa informação para realmente seja mudado a pratica de sala de aula.

As respostas das pedagogas evidenciam que há uma necessidade do fortalecimento da formação continuada dentro da realidade de cada escola, pois cada uma apresenta sua singularidade, necessitando de um olhar específico frente aos problemas elencados.

Para Inbernón (2011), a formação continuada deve ir além dos cursos, dotar o professor de instrumentos e possibilitar a interpretação de situações complexas que emergem no seu cotidiano. A formação continuada possibilita ao pedagogo compreender os desafios da prática diária, dar subsídios aos mesmos e de forma reflexiva apontar caminhos para as necessidades que emergem no contexto escolar.

O profissional prático reflexivo consegue superar a rotinização de suas ações e segundo Peres at al (2013, p. 03), "ao se deparar com situações de incertezas, contextualizadas e únicas, esse profissional recorre à investigação como forma de decidir e intervir”. 
As adversidades de situações que ele encontra, requer fortalecimento nos subsídios teóricos e metodológicos para refletir e intervir nessa realidade, não sendo viável aplicar o mesmo modelo de formação para todas as unidades escolares da mesma rede de ensino, pois, em cada comunidade escolar encontra-se diferentes especificidades.

Diante dos relatos dos pedagogos, é preciso que as formações sejam específicas de acordo com a demanda de cada escola, conforme as falas de P7 e P15:

\begin{abstract}
P7 - Nós temos uma formação contínua mesmo, ela acontece ao mesmo tempo semanal e semestral. Uma vez por semestre a gente faz a semana pedagógica, mas sempre surge a partir das necessidades que os professores levantam, a gente tem essa concepção de que as necessidades formativas deles dão um ponta pé inicial, aquilo que seria, os temas das semanas de formação.
\end{abstract}

P15 - A gente precisa muito da questão da formação continuada, tanto para nós enquanto equipe, para a equipe gestora e para os professores, porque a formação continuada é muito fragmentada, então a gente busca, a escola e a direção também buscam outros meios de trabalhar com os professores, trazendo palestrantes de fora nas semanas pedagógicas.

Foi possível constatar diante dos relatos, que as escolas fazem uma adequação das formações ofertadas pela mantenedora para atender a realidade local emergidas a partir das situações levantadas pelos professores. As formações ocorrem semestralmente na semana pedagógica $^{2}$ e semanalmente nos momentos de hora atividade ${ }^{3}$ do professor.

A seguir apresenta-se a categoria 02 que retrata a forma de como as informações são compartilhadas nas unidades escolares em que os pedagogos participantes da formação continuada desenvolvem seu trabalho.

A categoria 2 - Compartilhamento de informações, refere-se à contribuição do pedagogo para a formação continuada dos professores nas instituições em que trabalham. Desta forma, conhecer a realidade local é indispensável no fortalecimento de ações para a formação continuada e a troca de experiência com os seus pares.

Foi possível constatar nas vozes dos entrevistados a necessidade da articulação entre a equipe diretiva e a pedagógica. Ressalta-se na percepção dos pedagogos entrevistados que a formação continuada ocorre no ambiente escolar ou em ambientes externos. Na rede pública acontece em dois momentos distintos do ano letivo, sendo denominada de "Semana Pedagógica" e pode acontecer durante o horário de planejamento e estudo dos docentes, identificados como

\footnotetext{
2 A semana Pedagógica acontece nos primeiros e segundos semestres de cada ano e tem como objetivo promover a formação continuada dos profissionais da educação através de discussões pautadas em aportes teóricos relevantes sobre temas emergentes que afetam o cotidiano da sala de aula, bem como o processo de ensino e aprendizagem, de modo a fundamentar os profissionais da educação para o planejamento do semestre letivo (SEED/PR).

${ }^{3}$ A hora-atividade é um período da carga horária dos professores dedicado a atividades fora da sala de aula, que incluem planejamento, estudo e discussões voltadas para a constante melhoria da prática pedagógica (SEED/PR).
} 
"Hora de Permanência" e na Rede Municipal é denominada "Hora Atividade". Na rede privada constatamos nas entrevistas que além desses momentos já citados, os pedagogos e professores são convidados a realizarem cursos além de seus horários de trabalho, aos sábados ou no período noturno.

Placco, Almeida e Souza (2015, p. 18) salientam que as "Formações nas escolas ocorrem no horário de planejamento e por turno, em reuniões, nos horários de trabalho pedagógico coletivo, também chamados de horários de permanência dos professores".

As redes pública e municipal ofertam modelos sistematizados de momentos de estudos e de formação continuada, possibilitando atender as demandas dos pedagogos, oportunizando momentos de reflexão com seus pares visando a mudança nas práxis pedagógicas.

Os discursos dos pedagogos entrevistados relatam a importância da formação continuada, entretanto, declaram que elas precisam ter organização, ouvir a necessidade dos pedagogos e contribuir na prática cotidiana conforme relato de P3, P4 e P23:

P3 - Quando há organização, ela pode contribuir de uma melhor forma, saindo dos moldes pré-estabelecidos e consegue atender a uma demanda mais específica de cada docente.

P4 - A questão de ouvir as necessidades do professor, porque formação continuada não é só colocar o que é necessário para o aluno, mas o que é necessário para o professor, muitas vezes ele vem angustiado para a escola.

P23 - A escola e a gestão são bem abertas, então quando surge oportunidades a minha gestora incentiva que a gente busque, estude, contribua. Não há ditadura, nem empecilho, essa oportunidade de formação não precisei nem trocar ideia com a direção, pois já sabia que ela iria aceitar e apoiar, ela pensa que toda contribuição é bem-vinda.

As formações oferecidas nos espaços escolares são planejadas por meio das redes de ensino, sendo o papel do pedagogo aplicar aos docentes e as equipes administrativas. As mesmas não contemplam a especificidade da escola, pois não há um planejamento para a particularidade local. Relatam que se debruçam estudando o material oferecido pelas mantenedoras para fazerem a transposição didática e atender as devolutivas solicitadas após os encontros de formação.

Os pedagogos entrevistados mencionam que as temáticas são elaboradas pela mantenedora, muitas vezes precisam ser complementadas de diferentes formas para que possa ser aplicada aos docentes e muitas vezes buscam capacitação por conta própria visando atender suas necessidades, pois muitas formações ofertadas ocorrem juntamente com os professores o que não atendem suas necessidades específicas para o trabalho, conforme relato de P2, P3, P4, P21: 
P2- Na Rede Municipal de Curitiba hoje não tem formação para o pedagogo, você tem formação para os professores e o pedagogo tem que acompanhar e você tem formação para os diretores.

P3 - As formações com temáticas prontas. Às vezes, quando necessário, eu sento com um professor em particular e fazemos a troca de experiência.

P4 - Quando a gente consegue organizar intercalando dinâmicas, textos e frases que vão causar um determinado impacto e levar conhecimento ao professor, a gente percebe que é mais efetivo o trabalho na formação. Contribuição está em ouvir o professor e organizar a formação.

P21 - Como a gente tinha necessidade de trabalhar com educação inclusiva, eu fui buscar e fui fazer cursos para a gente atender dentro da nossa necessidade, então eu busco a minha formação para poder trabalhar com os professores.

A categoria 3 - Ações formativas - buscou-se compreender como a escola contribui para a formação profissional do pedagogo em sua trajetória. Foi possível perceber que na rede privada há investimento em formações, subsídios financeiros para cursos externos e aquisição de materiais para estudos. Na rede pública, no relato dos pesquisados, a maior contribuição são os desafios do cotidiano conforme abaixo:

P10 - A escola permite uma liberdade muito grande do profissional de sair da instituição para participar de um evento, investe por exemplo na educação, se você pedir algum livro ou uma realização de curso, nesta parte ela é bem presente.

P13 - Nós temos a webconferência com assessoria especializada e pedagógica e o incentivo a cursos de especialização, mestrado e doutorado, então há essa preocupação com a formação do pedagogo e dos demais professores também.

P14 - Sou desafiada por um professor, por um funcionário e $99 \%$ das vezes sou desafiada pelos meus alunos, sempre tenho que estar correndo atrás do que ainda não sei para poder dar retorno para esses alunos e para esses professores.

P16 - Experiências com realidades bem difíceis, conhecendo as famílias, perfil de famílias que hoje mudou muito. Esse conceito de família, resumindo a diversidade, me faz crescer, me traz experiência em todos os campos.

$\mathrm{Na}$ rede privada segundo os relatos dos entrevistados, ocorre formações diversificadas atendendo as necessidades. Os pedagogos demonstraram participar de formações ofertadas por grandes redes de ensino, das quais as suas escolas mantêm convênio, assim utilizam diferentes metodologias.

Quanto aos pedagogos da rede pública, evidenciou-se que ocorrem poucas formações, participam de encontros para repasse de informações, porém sem caráter de formação continuada.

Para os autores Placo, Almeida e Souza (2015) para que ocorra a mudança dessa realidade é necessário investimento de políticas de formação específica para os profissionais que exercem a coordenação pedagógica. Salienta-se a importância de formações específicas para o pedagogo 
tendo em vista a complexidade de seu trabalho, pois o mesmo perpassa por funções pedagógicas e técnicas e não há fortalecimento de ações reflexivas, segue uma lógica do fazer e resolver problemas emergentes.

Outros pedagogos relatam que é no cotidiano, na diversidade, organizando e reorganizando as práticas que a aprendizagem acontece. Ressalta-se a importância do trabalho colaborativo no contexto escolar conforme P15, P21 e P25:

\footnotetext{
P15 - aprendo com a disponibilidade, com a forma de organização, pessoas totalmente diferentes, assim, e que se complementam ... acho que todo dia.

P21 - aprendo com os alunos, são bem diversificados e a gente aprende a conhece-los, então o feedback que eles nos trazem é uma questão de formação, com os professores também ocorre a troca de informação.

P25 - A dinâmica do cotidiano faz a gente repensar muitas coisas, enquanto equipe pedagógica, planeja uma ação todo dia. No diálogo com o aluno e com professor, na escuta a gente se abre pra escutar o outro, isso faz a gente repensar todos os dias, em várias ações, ter que repensar, ter que mudar, outra forma de fazer.
}

A escola é um ambiente propício para a formação continuada, pois exerce um papel fundamental no desenvolvimento da comunidade escolar, apresenta caráter social e cultural que promove o repensar de novas aprendizagens, oportuniza o diálogo e as trocas de forma dinâmica.

Para Tardif (2014, p. 291), “a formação continuada concentra-se nas necessidades e situações vividas pelos práticos ${ }^{4}$ e diversifica suas formas: formação através dos pares, formação sob medida, no ambiente de trabalho integrada numa atividade de pesquisa colaborativa, etc.".

Percebe-se no relato dos pedagogos, que ocorrem aprendizagens na prática cotidiana, na troca com os colegas e na vivência com as famílias, o que foi percebido na pesquisa elaborada por Tardif sobre a prática profissional.

\section{Considerações finais}

A partir da percepção dos pedagogos que participaram da formação continuada ofertada, o objetivo de compreender suas percepções acerca da aprendizagem da formação continuada para o seu autodesenvolvimento, foi possível identificar a importância deste modelo formativo nesse universo pedagógico.

\footnotetext{
${ }^{4}$ É uma expressão utilizada por Maurice Tardif no seu livro Saberes Docentes e Formação Profissional (2014), para descrever que os professores são considerados práticos, refletidos que produzem saberes específicos ao seu próprio trabalho e são capazes de deliberar suas próprias práticas.
} 
A formação continuada se caracteriza como uma condição importante para a ressignificação e fortalecimento de ações, pois possibilita a reflexão, permitindo rever e transformar-se, dentro de um processo de emancipação para o desenvolvimento profissional.

Percebe-se que os pedagogos se identificam enquanto sujeitos do fazer pedagógico preocupados com as pessoas envolvidas neste processo, sendo que há uma intencionalidade em contribuir em seu ambiente escolar.

$\mathrm{Na}$ rede pública de ensino, foi possível perceber nos relatos dos pedagogos que a formação continuada específica ocorre de forma unitária, a mesma formação é oferecida para professores, gestores e pedagogos. Quando há um encontro para os pedagogos os temas promovidos pelos órgãos são de cunho burocrático com ênfase em quantificar dados ou de repasse de informações, com pouco caráter pedagógico.

Verificou-se que os pedagogos percebem que aprendem dentro da escola, no convívio com os seus pares, na diversidade e na complexidade de situações que ocorrem no ambiente escolar, assim, saem dos moldes tradicionais para reinventar e transformar a própria prática.

Constata-se que há poucos momentos de planejamento de ações para o desenvolvimento do trabalho pedagógico, as formações são deficitárias, fora da realidade escolar, atendendo apenas $\mathrm{o}$ interesse da mantenedora.

Relatam ainda que não há preocupação dos gestores no interior das unidades escolares públicas com a formação ou o incentivo dos pedagogos para participarem de formações continuadas em espaços diferentes, como cursos de extensão.

Foi possível identificar nas vozes dos pedagogos a angústia de transformar os seus afazeres diários em modelos de cumprir tarefas, de forma a resolver problemas cotidianos.

Já na rede privada, ocorre o fortalecimento da formação continuada por meio de assessorias especializadas dentro do contexto escolar, com o intuito de atender os problemas latentes, também há convênio com grandes redes de ensino e acontecem grupo de estudos e a trocas entre pares. Há incentivo financeiro para curso de pós-graduação e aquisição de materiais para enriquecer a prática.

Percebe-se após a análise que existe uma grande diferença em relação aos incentivos e organização na estrutura das formações continuadas, onde na rede pública não existe uma formação específica para os pedagogos, ficando os encontros apenas para repasse de informações, sem cunho pedagógico, porém, relatam que há grande aprendizado nos momentos de trocas com os professores, famílias, alunos e entre a própria equipe.

Constatou-se que é necessário maior investimento na formação continuada específica para os pedagogos da rede pública, tendo em vista que esses são os articuladores e mediadores de toda 
prática pedagógica que permeia a escola. Enquanto que na rede privada os incentivos financeiros e a oportunidade de participarem de formações específicas emprega segurança em sua prática profissional.

Enfim a formação continuada é uma necessidade de todo o profissional, seja na rede pública ou privada. Porém, a mesma precisa ter fundamentos teóricos e metodológicos, que enfatizem a reflexão sobre a prática, levando a uma mudança de postura frente à equipe de trabalho.

Consideramos também que a partir das análises das questões elencadas, sobre a importância da participação do pedagogo em um Programa de Formação Continuada, foi possível responder à questão norteadora deste estudo. Concluímos que a formação ofertada possibilitou a reflexão dos participantes sobre a sua própria prática, levando ao autoconhecimento, ou seja, despertando a capacidade autorreflexiva.

\section{Referências}

ALMEIDA, CM.; SORAES, K, D, C. Pedagogo Escolar: as funções supervisora e orientadora. Curitiba:Intersaberes,2012.

BATISTA, G. O fazer e o Saber Fazer de Professores de Educação Física Escolar Dentro de um Programa de Formação Continuada. Tese de Doutorado (2019), PUC-PR. Disponível em https://metacognicao.com.br/?p=2937. Acesso 26/06/2021.

BRASIL. Ministério da Educação. Lei de Diretrizes e Bases da Educação Nacional. DB 9.394, de 20 de dezembro de 1996. Brasília/DF: Poder Legislativo, 1996.

BRECKENFELD, E. J., N. GUIRAUD, L.; ROMANOWSKI, J.P. CONSIDERAÇÕES SOBRE A FORMAÇÃ O CONTINUADA DO PEDAGOGO ESCOLAR NO SISTEMA DE ENSINO PÚBLICO ESTADUAL PARANAENSE (2004-2008): POSSIBILIDADES E LIMITES. Disponível em https://educere.bruc.com.br/arquivo/pdf2009/3380_1583.pdf. Acesso em 16/11/2020.

FREIRE, Paulo. Pedagogia da autonomia: saberes necessários à prática educativa. 20ed. São Paulo: Paz e Terra, 2001.

GARCIA, Regina Leite et al. A formação da professora alfabetizadora: reflexões sobre a pratica. São Paulo: Cortez, 1996.

GOMES, R. Organização, processamento, análise e interpretação de dados: o desafio da triangulação. In: MINAYO, Maria Cecília de Souza; ASSIS, Simone Gonçalves de; SOUZA, Edinilsa Ramos de. Avaliação por triangulação de métodos: abordagem de programas sociais. Fio Cruz, 2005.

IMBERNÓN, F. Formação docente e profissional: formar-se a mudança e a incerteza. Tradução Silvana Cobucci Leite. 9. Ed. São Paulo Cortez, 2011. 
LIBÂNEO, J.C. Organização e gestão da escola: teoria e prática. São Paulo: Heccus Editora, 2018.

MINAYO, M. C. S.; COSTA, A. P. Fundamentos Teóricos das Técnicas de investigação qualitativa. Revista Lusófona de Educação, n. 40, p.139-153, 2018.

MANARIN, C.; PORTELINHA, Â. M. S. O coordenador pedagógico frente aos desafios da constituição de sua profissionalidade. Dialogia, São Paulo, n. 33, p. 192-204, set./dez. 2019.

NÓVOA, A. Firmar a posição como professor, afirmar a profissão docente. Cadernos de Pesquisa v.47 n.166 p.1106-1133 out./dez. 2017.

PERES, M.R; RIBEIRO, R.C; RIBEIRO, L.L.L.P; COSTA, A.F.R; ROCHA, V. A Formação Docente e os Desafios da Prática Reflexiva. Revista Educação. Vol. 38, n 02, p. 289-304, maio/ago. 2013. Santa Maria- RS [acesso em 06 dez 2021]. Disponível em https://periodicos.ufsm.br/index.php/reveducacao/article/view/4379.

PLACCO, Vera Maria Nigro, ALMEIDA, Laurinda Ramalho (orgs). O coordenador pedagógico no espaço escolar: articulador, formador e transformador. São Paulo: Edições Loyola, 2015.

PLACCO, V. M. N. S.; SOUZA V. L. T.; ALMEIDA, L. R. O Coordenador Pedagógico: Aportes à Proposição De Políticas Públicas. Disponível em https://www.scielo.br/j/cp/a/WPF5PzGd5zS3QWZPYNhWYDQ/abstract/?lang=pt. Acesso em 12/07/2021.

PORTILHO, E. M.L.; PAROLIN, I.C.H.; BARBOSA, L.M.S. Formação continuada de pedagogos escolares: o significado de grupo e comunicação na prática pedagógica. Disponível https://portalperiodicos.unoesc.edu.br/roteiro/article/view/24333 acesso dia 07/10/2021.

PORTILHO, E. Como se aprende? Estratégias, estilo e metacognição. Rio de Janeiro: Wak Ed., 2011.

PIMENTA, Selma Garrido. O estágio na formação de professores: unidade teórica e prática. 3. ed. São Paulo: Cortez, 2005.

SILVA, C. S. R. A relação recíproca entre o pedagogo e a cultura escolar em uma escola estadual de Curitiba - PR e os impactos da pandemia da Covid-19. 2021. Tese (Doutorado) - Pontifícia Universidade Católica do Paraná, Curitiba.

TARDIF, M. Saberes Docentes e Formação Profissional. 17. Ed. Petrópolis, RJ; Vozes, 2014. 